\title{
EXPOSING PRACTICAL, PSYCHOLOGICAL AND PEDAGOGICAL SHADOW SIDES OF EXPERIENTIAL LEARNING
}

April Wright (corresponding author)

Business School

University of Queensland

Colin Clark Building

St Lucia

QLD 4067

Australia

a.wright@business.uq.edu.au

\section{Ross Strong}

Business School

University of Queensland

Colin Clark Building

St Lucia

QLD 4067

Australia

m.edwards@business.uq.edu.au

\author{
Paul Hibbert \\ School of Management \\ University of St Andrews \\ St Andrews \\ Fife \\ KY16 0UH \\ UK \\ ph24@st-andrews.ac.uk \\ Marissa Edwards \\ Business School \\ University of Queensland \\ Colin Clark Building \\ St Lucia \\ QLD 4067 \\ Australia \\ r.strong@business.uq.edu.au
}

\begin{abstract}
This paper is based first-person experience with Experiential Learning (EL) practices in an undergraduate introductory management course. We consider how a challenging EL activity, based on volunteering during recovery from a catastrophic flood event, exposed three shadow sides of EL. These shadow sides of EL, that often remain hidden to educators, are practical, psychological and pedagogical. We provide a characterisation of each of these shadow sides and outline strategies for managing them. We also discuss the general applicability of our insights, including tentative theoretical extensions to Kolb’s (1984) EL theory. We conclude by considering the potential for the shadow sides of EL to emerge in circumstances that are less confronting and extreme than those encountered by our students.
\end{abstract}

Keywords: experiential learning, assessment of learning, undergraduate, emotion, reflection 


\section{EXPOSING PRACTICAL, PSYCHOLOGICAL AND PEDAGOGICAL SHADOW SIDES OF EXPERIENTIAL LEARNING}

This paper examines the shadow sides of experiential learning (EL) based on our experiences in an undergraduate introductory management course in the aftermath of the 2011 Queensland floods in Australia (for more information see Wright, Nichols, McKechnie, \& McCarthy, 2013). When planning the EL activity one month after the flood event, instructors liaised with a local government agency and organized for students to sign up on the agency website to volunteer to assist community organizations with their flood recovery work. Volunteering for a few hours was intended to provide students with a meaningful and socially-responsible experience of management concepts, which they would later reflect on and analyse in a written assignment. The intended outcomes involved deepening understanding of management concepts by engaging students in the following EL cycle (Kolb, 1984): a concrete experience of volunteering with a community organization $\rightarrow$ reflective observation of their personal volunteering experience $\rightarrow$ conceptualisation of the experience using course theories and scholarly literature $\rightarrow$ active experimentation with how these insights could be applied in the student's future management career. Students were required to write up their EL cycle in an assessable assignment.

Our first-person experience with a volunteering activity linked to a catastrophic flood event exposed three shadow sides of EL that often remain hidden to educators. We label these shadow sides as practical, psychological and pedagogical. We describe each shadow side in turn, along with selected examples and connections to other teaching contexts, and suggest strategies that educators can apply to manage the shadow side. We then offer some speculative directions for theoretical development and close with practical implications.

\section{Practical Shadow Side of EL}


A practical shadow side arises because the educator's plans for the EL cycle must be put into action by students in situated circumstances (Suchman, 1987; Tomkins \& Ulus, 2015). In the case of our post-flood EL, situated circumstances prevented some students securing the concrete volunteering experiences needed to start the EL cycle. For example, students who took on paid casual work to replace flood-damaged computers and cars, and/or to contribute to their own living costs when family homes and businesses were flooded, found the volunteering timeslots on the agency website conflicted with work and university commitments. Students who had lost laptops in the floods had to sign up to volunteer using the university’s computer terminals, which were insufficient to meet campus-wide demand, and the agency’s website did not always function effectively while the city's technological infrastructure recovered from the floods. For other students, the situated circumstance of not owning a car meant they could not travel to volunteering locations because the city's public transport infrastructure was damaged by the floods.

While these examples are specific to our post-flood EL activity, the presence of a practical shadow side is not unique to the aftermath of natural disasters. Every student is situated in a personal lifeworld (Reynolds, 2009) that constrains their agency to participate in EL activities outside of the classroom, including small-scale company site visits and field trips (McCarthy, 2001) and large-scale immersive international study-abroad exchanges (Sachau, Brashe, \& Fee, 2010; Sroufe, Sivasubramaniam, Ramos, \& Saiia, 2015). The social relationships, family responsibilities, work-study priorities, and access to resources in a student's personal lifeworld create situated circumstances that restrict how and when an individual can engage in concrete experiences outside of the classroom in EL cycles.

We suggest that educators can apply three strategies to manage the practical shadow side of EL. First, educators can create opportunities for EL that reduce the negative impact of situated circumstances. We created more accessible volunteering experiences for students 
through instructor-led field trips with free transport to locations where community organizations were coordinating flood-recovery activities.

Second, educators can offer substitute experiences to increase student's agency in their situated circumstances. When circumstances made volunteering difficult, we offered students the option of undertaking desk research to explore how various government agencies managed flood response and recovery. While this substitute experience did not match the lived authenticity of a volunteering field trip, providing students with a choice among concrete experiences increased their agency in structuring the EL cycle to fit with their unique family, work and resource circumstances after the floods. Substitute experiences for field trips in other courses might include playing simulation games (Nichols \& Wright, 2015; Salas, Wildman, \& Piccolo, 2009) or watching films (Smith, 2009).

Third, educators should adapt EL assessment requirements to make appropriate accommodations for individual situated circumstances. We gave students whose living circumstances were severely impacted by the floods extensions on due dates and flexibility to submit hand-written assignments if their computer was damaged. Together, these three strategies can help educators to manage the practical shadow side of EL.

\section{Psychological Shadow Side of EL}

EL activities have a psychological shadow side which arises when the educator's choice of concrete experience imposes a burden on a vulnerable student's psychological wellbeing. Our decision to base the experiences and reflections in our EL cycle on the recent flood event had the potential to cause psychological distress. Students whose homes, businesses and possessions were damaged in the floods had very personal and traumatic experiences of loss. Some of these individuals found it healing to engage in the EL activities we had designed around the flood event. Others anxiously contacted instructors and reported 
that participating in volunteering fieldwork experiences, or the substitute experience of a research project contextualised to the flood, was too distressing.

We argue that all EL activities have a psychological shadow side that arises from a combination of the educator's choice of context and form. Contextualising EL to a recent traumatic event in the natural, political, economic, or social environment of a local or national community - as we did immediately after the 2011 Queensland floods - heightens this psychological shadow side because traumatic experiences produce emotional reactions that can be overwhelming in the moment of crisis (Bloom, 2013). However, using past traumatic events where human lives were lost - like the 9/11 terrorist attacks (Fukami, 2002) as contexts for EL activities can still leave students in a psychologically difficult state. In addition to the context, the particular form the EL activity takes can impose a psychological burden on a vulnerable student. Not all students are developmentally ready or sufficiently mature for EL (Lund Dean \& Jolly, 2012) and can find the lack of instructor control and direction to be confusing and frustrating (Allen, 2018). EL can trigger distressing emotions (McCormick, 1990; Vince, 1998), such as fear of failure. Introverted students, and students for whom English is a second language, may feel especially vulnerable when participating in EL activities that require public performance such as role plays (Simpson, Sturges, \& Weight, 2009).

We recommend two strategies for managing the psychological shadow side regardless of whether EL is contextualised within a recent traumatic event like a flood or within other emotionally-neutrally and distant events. First, educators should develop inquiry mechanisms to identify vulnerable students who may be at risk of psychological harm from EL activities. Simola (2016: 18) contends that educators have an ethical obligation to "show sensitivity to [the] social, emotional and physical risk” associated with an EL activity. We acknowledge that this can be challenging because it may not be immediately apparent to an 
educator which students are vulnerable to distress from the EL context and form. In our postflood EL, we relied on self-identification inquiry mechanisms to bring vulnerable students to our attention. We announced in lectures that any student who had concerns about the floodcentric EL activities should contact instructors, while the University encouraged all students impacted by the floods to seek psychological and material support through institutional channels. Other educators may wish to supplement self-identification mechanisms with instructor-facilitated mechanisms to gain deeper insight into the developmental readiness of students to engage in EL. Educators could, for example, survey students’ personality characteristics, preferred learning styles and emotional intelligence to identify and support those individuals most likely to experience frustration or distress from the educator's choices of EL context and form.

Second, educators should work with vulnerable students to construct a safe conceptual space for EL (Kisfalvi \& Oliver, 2015). This strategy includes considering whether - and how - educators and other professionals can support students to develop social resources and greater personal resilience to work through emotional trials (Beech, 2017). For some students, however, educator and/or professional support will not be sufficient to overcome the risk of psychological harm. Modification of EL activities to provide students with confidence and protection from potential harm, or replacement with an alternative activity, is then required (Simola, 2016). We offered a small number of students - who had self-identified as severely distressed by the flood event - an alternative activity. Instead of engaging in community volunteering or desk research linked to the floods, these students were permitted to base their EL cycle on a business case study. This alternative EL removed the requirement to engage intellectually and experientially with the flood event, thereby reducing the risk of psychological harm. Educators who offer students a 'safe' alternative EL 
activity must ensure that this alternative is equitable, constructively aligned with the curriculum, and continues to assess the learning aims of the original EL cycle.

\section{Pedagogical Shadow Side of EL}

Finally, the pedagogical shadow side emerges when students' reflection on, and conceptualisation of, their experience does not align with the educator's learning goals for the EL activity (Hibbert, Beech, \& Siedlok, 2017; Kolb \& Kolb, 2005). The intended mechanism of learning in our post-flood EL was student's reflection on their experience of volunteering to assist a community organization with flood recovery efforts. Reflection was envisioned to lead to attempts to conceptualise this experience using course theories, followed by active experimentation with how these theories could be applied in the student's future career. However, some students focused their reflection on the drama of the flood event and made little attempt to conceptualise their experience within a framework of course theory. Others described their frustration interacting with the government agency’s volunteering website and failed to critically analyse their personal experience of volunteering work.

The pedagogical shadow side arises because EL gives the student, rather than the educator, control of the learning process through how they reflect on and make sense of their own personal experience (Beard \& Wilson, 2006; Kolb, 1984). Thus, students can apply EL in ways other than those intended by educators even when the concrete experience that begins the EL cycle is not as dramatic as a recent flood event. For example, one of the authors has taught a strategy class involving project work with industry clients. Some students became so focused on their sense of professional achievement that they resisted engaging in an EL cycle of balanced, theoretically-informed critique of their experiences. Miller and Maellaro (2016) similarly found that students' reflective observations in lean operations and leadership courses did not always lead to the conceptualizations intended by educators in the EL cycle. 
We suggest that two strategies may be helpful to educators in managing the pedagogical shadow side. First, educators should elaborate learning goals and their links to grading criteria in task descriptions of EL and associated marking rubrics. In our post-flood EL, we provided a detailed description of the intended learning goals and developed explanatory statements of grading criteria and standards to align with the four stages of the EL cycle. In lectures, we drew student's attention to how the marking requirements were linked to their course-specific engagement in an EL cycle and not to their general perceptions of the flood event. Making learning goals from EL more transparent better prepares students to engage in meaningful reflection, conceptualization and experimentation of their own lived experience within the context of course teaching.

Second, educators should facilitate post-experience debriefs using guided reflection questions. We provided students with reflection logs that: 1. encouraged journaling about the experience as soon as possible after volunteering with the community organization; and 2. prompted students to begin the conceptualisation stage of EL by teasing out the connections between their volunteering experiences and course theory, which subsequently formed the basis of shared reflection and collective dialogue in class. Facilitating post-experience debriefs is more readily operationalised when an easy-to-engage framework for reflection is applied, such as Knowles, Holt and Swanson’s (2011) principles of adult learning, as recommended by Greenfield and Hibbert (2017), or Raelin’s (2008) suggestions for reflection in and on work-based learning. Educators are likely to be aware of other reflective frameworks and can explore those that best fit their EL context and learning goals.

\section{Suggestions for theoretical development}

The primary purpose of our paper has been to explicate the three shadow sides of EL and identify strategies for their management. Given the paper's grounding in educators’ personal experiences, we are cautious in making claims about theory building. We can, 
however, offer some tentative speculations about how our insights open up avenues for further research. Building on Kolb’s (1984) EL theory, we speculate that stages in the EL cycle need to be scaffolded to accommodate for the three shadow sides. Figure 1 illustrates a set of tentative relationships between shadow-side scaffolding mechanisms and Kolb’s theoretical model which we invite future research to explore. First, identifying practical and psychological shadow sides before instructors design concrete experiences, better prepares students to begin the EL cycle. Second, scaffolding the transition from concrete experience to reflective observation through safe spaces and elaborated goals reduces the psychological and pedagogical shadow sides for students. Third, scaffolding the transition from reflective observation to abstract conceptualisation through post-experience debriefs reduces the pedagogical shadow side by helping students reflect in course-appropriate ways. Finally, scaffolding both abstract conceptualisation and future active experimentation through adaptation of assessment requirements reduces the practical shadow side for students in situated circumstances.

Figure 1 about here

We offer the insights summarised in Figure 1 tentatively as areas for further investigation. Research is needed to explore the extent to which the model is more or less salient in particular EL contexts. This may include a consideration of extended and varied experiential learning contexts, when multiple experiential exercises are offered in particular patterns. For example, experiential learning opportunities may be offered in sequence, across a particular class or program, to support a virtuous cycle of learning. Where this sequential approach is in place, educators may wish to conduct research on the use of the model with a focus on how it helps to facilitate the development of students' abstract conceptualisations, in readiness for active experimentation in each successive new context. Other patterns of 
experiential education that focus on deliberate and/or radical variations in context may place an emphasis on other part(s) of the experiential learning cycle - perhaps reflective observation - and suggest a need to research how our model supports the scaffolding interventions that are most salient for that pattern. However, the overall experiential learning process remains a cycle and for that reason we speculate that while emphasis may vary, considering scaffolding across the whole cycle, as envisaged in our model, may still be necessary. This is because of the potential for the shadow sides to impact differently on different students.

Empirical research is also, therefore, required to examine the comparative conditions under which the three shadow sides emerge for different types of students as well as to assess the impact of our theorised scaffolding mechanisms on Kolb’s EL cycle. While each of the scaffolding mechanisms in Figure 1 suggests opportunities for empirical investigation, it is beyond the scope of this short paper to outline a detailed research agenda.

\section{Implications for Management Educators}

In concluding our paper, we consider the broader implications for teaching and learning by exploring the question of whether the three shadow sides we exposed are unique to EL activities based on difficult experiences like flood events. We have already alluded to factors that lead us to think the three shadow sides are generalizable beyond our particular EL context. First, all students are situated in particular lifeworlds that constrain their capacity to engage in concrete experiences outside of scheduled classes, opening up a practical shadow side that educators need to consider to when designing EL activities. Second, in relation to the psychological shadow side, students have different vulnerabilities that may be triggered by the educator's choice of context and form of EL activities whether or not these are linked to recent traumatic events like a flood. Third, when considering the pedagogical shadow side, student's own interests and motivations can limit or misdirect their reflection, 
conceptualisation and experimentation of concrete experiences away from the educator's intended aims at different stages of the EL cycle even in 'benign' EL projects. Thus, given the variety of possibilities and inter-relationships between these factors, we speculate that one or more of these shadow sides are ever-present in EL. While the three shadow sides are therefore potentially intrinsic to EL activities, we suggest that they are most visible to educators when the concrete experience that forms the basis for the EL cycle engages student's deepest emotions. 


\section{References}

Allen, S. 2018. Yes! And . . . I'm so tired of experiential learning. Journal of Management Education, 42(2): 306-312.

Beard, C. M., \& Wilson, J. P. 2006. Experiential Learning: A Best Practice Handbook for Educators and Trainers. London, UK: Kogan page Publishers.

Beech, N. 2017. Identity at Work: An enquiry-based approach to therapeutically-inspired management. International Journal of Management Reviews, 19(3): 357-370.

Bloom, S. 2013. Creating Sanctuary: Toward the Evolution of Sane Societies (Second ed.). New York: Routledge.

Fukami, C. V. 2002. 9/11 montage: Professors remember. Academy of Management Learning and Education, 1(1): 14-37.

Greenfield, G., \& Hibbert, P. 2017. Reflective and reflexive practice in the flipped classroom. In C. Reidsema, L. Kavanagh, R. Hadgraft, \& N. Smith (Eds.), The Flipped Classroom: Practice and Practices in Higher Education. Singapore: Springer.

Hibbert, P., Beech, N., \& Siedlok, F. 2017. Leadership formation: interpreting experience. Academy of Management Learning and Education, 16(4): 603-622.

Kisfalvi, V., \& Oliver, D. 2015. Creating and maintaining a safe space in experiential learning. Journal of Management Education, 39(6): 713-740.

Knowles, M., Holton, E., \& Swanson, R. 2011. The Adult Learner (7th ed.). Oxford: Butterworth-Heinemann.

Kolb, A. Y., \& Kolb, D. A. 2005. Learning styles and learning spaces: Enhancing experiential learning in higher education. Academy of Management Learning and Education, 4(2): 193-212.

Kolb, D. A. 1984. Experiential Learning Theory: Experience as the Source of Learning and Development. Englewood Cliffs, NJ: Prentice Hall. 
Lund Dean, K., \& Jolly, J. P. 2012. Student identity, disengagement and learning. Academy of Management Learning and Education, 11(2): 228-243.

McCarthy, J. F. 2001. Learning from the battle: The Gettsburg staff ride. Journal of Management Education, 25(5): 495-515.

McCormick, D. W. 1990. The painful emotions of prior experiential learning assessment. Adult Learning, 2(2): 26-28.

Miller, R. J., \& Maellaro, R. 2016. Getting to the root of the problem in experiential learning: Using problem solving and collective reflection to improve learning outcomes. Journal of Management Education, 40(2): 170-193.

Nichols, E., \& Wright, A. L. 2015. Using the Everest team simulation to teach threshold concepts. Journal of Management Education, 39(4).

Raelin, J. 2008. Work-Based Learning. San Francisco: Jossey Bass.

Reynolds, M. 2009. Wild frontiers: Reflections on experiential learning. Management Learning, 40(4): 387-392.

Sachau, D., Brashe, N., \& Fee, S. 2010. Three models for short-term study abroad. Journal of Management Education, 34(5): 645-670.

Salas, E., Wildman, J. L., \& Piccolo, R. F. 2009. Using simulation-based training to enhance management education. Journal of Management Education, 8: 559-573.

Simola, S. 2016. Realising the promise of experiential learning in poverty-related management education. In M. Gudić, C. Parkes, \& A. Rosenbloom (Eds.), Responsible Management Education and the Challenge of Poverty: A Teaching Perspective (pp. 9-22). Greenleaf: Sheffield, UK.

Simpson, R., Sturges, J., \& Weight, P. 2009. Transient, unsettling and creative space: Experiences of liminality through the accounts of Chinese students in a UK-based MBA. Management Learning, 41(1): 53-70. 
Smith, G. W. 2009. Using feature films as the primary instructional medium to teach Organizational Behavior. Journal of Management Education, 43(4): 462-489.

Sroufe, R., Sivasubramaniam, N., Ramos, D., \& Saiia, D. 2015. Aligning the PRME: How study abroad nurtures responsible leadership. Journal of Management Education, 39(2): 244-275.

Suchman, L. A. 1987. Plans and situated actions: The problem of human-machine communication. New York, N.Y.: Cambridge University Press.

Tomkins, L., \& Ulus, E. 2015. ‘Oh, was that “experiential learning”?!’ Spaces, synergies and surprises with Kolb’s learning cycle. Management Learning, 47(2): 158-178.

Vince, R. 1998. Behind and beyond Kolb’s learning cycle. Journal of Management Education, 22(3): 304-319.

Wright, A. L., Nichols, E., McKechnie, M., \& McCarthy, S. 2013. Combining crisis management and evidence-based management: The Queensland floods as a teachable moment. Journal of Management Education, 37: 135-160. 


\section{FIGURE 1: Scaffolding for Shadow Sides in Kolb’s Experiential Learning Theory}

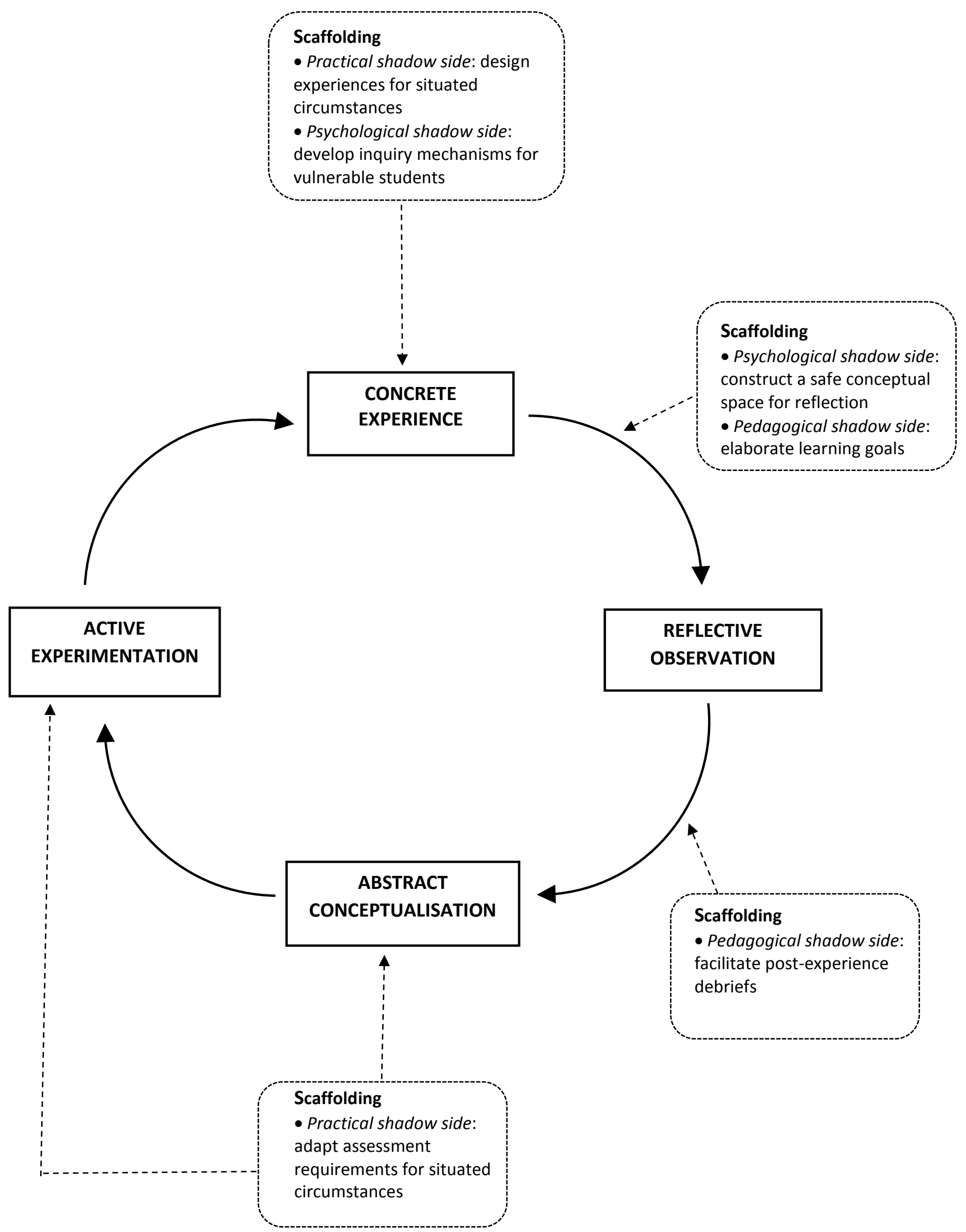

